\title{
Efficacy of plasma vascular endothelial growth factor in monitoring first-line chemotherapy in patients with advanced non-small cell lung cancer Sachin Kumar' ${ }^{1}$, Randeep Guleria*1, Vikas Singh¹, Alok C Bharti², Anant Mohan ${ }^{1}$ and Bhudev C Das ${ }^{3}$
}

Address: ${ }^{1}$ Department of Medicine, All India Institute of Medical Sciences (AIIMS), Ansari Nagar, New Delhi-110029, India, ${ }^{2}$ Division of Molecular Oncology, Institute of Cytology and Preventive Oncology, I-7, Sector-39, Noida, Uttar Pardesh-201301, India and ${ }^{3}$ Dr. B. R. Ambedkar Centre for Biomedical Research, University of Delhi (North Campus), Delhi-110007, India

Email: Sachin Kumar - sksingla@gmail.com; Randeep Guleria* - randeepg@hotmail.com; Vikas Singh - meetvsingh@yahoo.com; Alok C Bharti - alokchandrab@yahoo.com; Anant Mohan - anantmohan@yahoo.com; Bhudev C Das - bcdas48@hotmail.com

* Corresponding author

Published: 3 December 2009

BMC Cancer 2009, 9:42I doi:|0.|| |86/|47|-2407-9-42|
Received: 3 August 2009

Accepted: 3 December 2009

This article is available from: http://www.biomedcentral.com/I47/-2407/9/42 I

(C) 2009 Kumar et al; licensee BioMed Central Ltd.

This is an Open Access article distributed under the terms of the Creative Commons Attribution License (http://creativecommons.org/licenses/by/2.0), which permits unrestricted use, distribution, and reproduction in any medium, provided the original work is properly cited.

\begin{abstract}
Background: Along with the development of new cancer therapeutics, more effective tools for the estimation of response to therapy and prediction of disease progression are required for the better management of inoperable cancer patients.
\end{abstract}

Methods: We studied I 34 newly diagnosed and primarily untreated advanced non-small cell lung cancer patients and 100 controls. Forty two patients received platinum-based chemotherapy. Plasma VEGF levels were quantified in all samples at baseline and also before second and third chemotherapy cycle in 42 patients and correlated with response to therapy as assessed by computed tomography after the third chemotherapy cycle.

Results: We observed that, patients who went into remission had significantly lower baseline VEGF levels before second and third cycles of chemotherapy when compared with patients with no change and progression. Plasma VEGF levels showed a greater decrease from cycle I to 2 and from cycle I to 3 in patients who showed remission in comparison to those with no change or progression. Plasma VEGF levels before the second cycle detected poor response to therapy with a sensitivity and specificity of $76.9 \%$ and $75.0 \%$, respectively (area under the ROC curve $=0.724$ ). Early prediction of disease progression was achieved with a sensitivity and specificity of $71.4 \%$ for plasma VEGF before cycle 2 (area under the ROC curve $=0.805$ ). The kinetics of VEGF form cycle I to 2 and cycle I to 3 also gave significant information for predicting disease progression as well as insufficient therapy response.

Conclusion: Monitoring of plasma VEGF levels during the course of first-line chemotherapy could identify patients who are likely to have insufficient response to therapy and disease progression at an early stage. This may help in individualizing treatment and could lead to better management of the advanced stage lung cancer. 


\section{Background}

Lung cancer is one of the commonest neoplasms all over the world with approximately 1.35 million new cases worldwide in 2002 [1]. It is the most devastating cause of cancer-related deaths with more than 1.18 million deaths in 2002 [1]. Survival at 5 years measured by the SEER program in the United States is $15 \%$, the best recorded at the population level. The average 5 year survival in Europe is $10 \%$, not much better than the $8.9 \%$ observed in developing countries [1]. The poor outcome is attributable to the fact that almost two-third of cases are diagnosed when loco-regional and/or metastatic extension has already occurred [2]. The only treatment available at this stage is chemotherapy and/or radiotherapy. Although response rates for chemotherapy and radiotherapy are low, several studies have demonstrated moderate beneficial effects concerning survival, time to disease progression, and quality of life when compared with best supportive care [3]. The current staging investigations after cytotoxic therapies, like chemotherapy and/or radiotherapy, involve imaging procedures, like computed tomography (CT) and positron-emission tomography (PET)-CT. However, these procedures can monitor only macroscopic alteration of tumor mass, that too after several cycles of chemotherapy (2-3 cycles of chemotherapy and/or radiotherapy). In addition, they also have a risk of exposure to harmful radiation to the patient. Thus, there is a growing need for a simple tool that can help in evaluating the prognosis, monitor the effect of treatment and most importantly predict response to therapy at an early stage. One potential approach could be the quantification of tumor markers as they take into account the heterogeneity of the tumor mass which contain active, silent, apoptotic and necrotic part and they also represent the activity of the residual tumor disease. Therefore, any change in their levels should reflect the change in the tumor mass due to cytotoxic therapies, which mean that they can potentially provide a sensitive and cost-effective method for the prediction of prognosis of cancer patients. Further, serial assessment of tumor markers during cytotoxic therapies may help in predicting response to therapy at an early stage. This would help in optimizing disease management on an individual basis. In non-small cell lung cancer patients, several tumor markers, like CEA, CYFRA 21-1, and nucleosomes have shown considerable potential for predicting diagnosis, prognosis and therapy monitoring [4-9]. However, their potential in a clinical set-up is yet to be realized.

There is now an increasing recognition of the importance of targeted therapies, especially anti-angiogenesis therapies, in solid tumors to improve the overall survival or progression free survival. The two most common approaches currently being explored are i) antibodies to vascular endothelial growth factor (VEGF) or soluble receptors that inhibit the binding of VEGF to its receptor and ii) tyrosine kinase inhibitors blocking downstream signaling from membrane bound tyrosine kinase receptors. It is therefore becoming essential to study the profile of circulating VEGF during cytotoxic therapies in an effort to evaluate its potential in predicting prognosis, response to therapy, and disease progression. We hypothesized that monitoring VEGF levels during the course of cytotoxic therapy may have the potential to predict the clinical benefits in terms of prognosis and response to therapy in advanced NSCLC patients.

In the present study, we investigated the plasma levels of VEGF in a homogeneous group of patients with newly diagnosed and advanced NSCLC during first-line platinum-based chemotherapy to analyze the utility of VEGF for the prediction of insufficient response to therapy and disease progression. In addition, we looked for any correlation between pre-treatment plasma levels of VEGF with various clinico-pathological parameters in patients with non-small cell lung cancer.

\section{Methods Subjects}

We evaluated 134 newly diagnosed and primarily untreated advanced stage lung cancer patients and 100 age-matched controls (patients without malignancy). All subjects were enrolled from Out Patient Department of Medicine, All India Institute of Medical Sciences, New Delhi, India between years 2006-2009. For all patients, a diagnosis of lung cancer was confirmed by the histologic examinations of biopsy and/or cytology specimens obtained during fiberoptic bronchoscopy or with a CTguided procedure. Pre-treatment evaluation also included evaluation of Eastern Cooperative Oncology Group performance status (ECOG), X-ray and computed tomography (CT) scan of the chest and upper abdomen. If necessary, a CT or magnetic resonance imaging (MRI) scan of the brain, and radionuclide bone scan was performed. All the patients were staged according to the American Thoracic Society TNM classification [10]. Epidemiological data including demographics, family history, risk factors, occupational exposure, and histopathological data was recorded. Forty two (42) of these patients received platinum-based chemotherapy for a minimum of 3 cycles. In these patients, response to therapy was classified according to the WHO guidelines defining "partial remission" $(\mathrm{R})$ as tumor reduction $\geq 50 \%$, "progression" (P) as tumor increase $\geq 25 \%$ or appearance of new tumor manifestations, and "no change" (NC; stable disease) as tumor reduction $<50 \%$ or increase $<25 \%$ [11].

\section{Measurement of circulating plasma VEGF}

Venous blood was collected in sterile EDTA-coated vials from all subjects at baseline (BV1). Blood was also col- 
lected before second (BV2) and third (BV3) cycles of chemotherapy from 42 patients receiving platinum-based chemotherapy. Within one hour, samples were centrifuged $(2500 \mathrm{~g}, 10 \mathrm{~min})$, and the plasma was removed, aliquoted and stored at $-80^{\circ} \mathrm{C}$ until analysis. The VEGF was assayed by commercially available sandwich enzymelinked immunosorbent assay kits (Calbiochem, Darmstadt, Germany) according to the manufacturer's instructions. The limit of sensitivity of the VEGF assay was $9.0 \mathrm{pg} /$ $\mathrm{mL}$. The coefficient of variation was less than $5.0 \%$. The study was approved by the institute's ethics committee. Informed written consent was obtained from all the subjects.

In the present study, we compared plasma VEGF levels in patients with progressive disease $(\mathrm{P})$ with those having remission and stable disease $(\mathrm{R}+\mathrm{NC})$ to predict disease progression (evaluation 1). Also, plasma VEGF levels in patients with remission (R) were compared with those having progressive and stable disease $(\mathrm{P}+\mathrm{NC})$ in an effort to predict insufficient response to therapy (evaluation 2 ).

\section{Statistical analysis}

To test the association of therapy at time of staging investigations after $3^{\text {rd }}$ cycle of chemotherapy with overall survival of the patients, Kaplan-Meier curves and log-rank analyses were established for various response groups.

Concerning the biochemical variables, the baseline values of all markers before the first, second, and third cycles (BV1, BV2, and BV3) and the percentage changes (BV1-2 and BV1-3) were considered for statistical analyses. In a first step, all biomarkers were evaluated on their power to univariately discriminate between (a) patients with progression $(\mathrm{P})$ and non-progression ( $\mathrm{R}+\mathrm{NC}$; evaluation 1$)$ as well as between (b) patients with remission (R) and non-remission $(\mathrm{P}+\mathrm{NC}$; evaluation 2$)$ by Wilcoxon test. To identify the diagnostic biomarker for insufficient therapeutic efficacy and progression, receiver operating characteristic curves and corresponding areas under the curve (AUC) was calculated. In addition, sensitivity and specifi- city (with 95\% confidence interval) was calculated at defined cut-off VEGF levels for detecting insufficient therapeutic efficacy and progression.

Demographic information between cases and controls was compared using unpaired t-test for continuous variables and Chi-square test for categorical variables. The comparison of the different patient groups and the circulating VEGF variables was performed using unpaired ttest. All statistical comparisons for VEGF were performed with logarithmically transformed data as VEGF-values were not distributed normally. Median and interquartile ranges for VEGF is given because of their skewed distributions. $\mathrm{p}$ value $<0.05$ was considered statistically significant. All statistical analyses were performed using SPSS software program for Windows (SPSS 9.1; STATA Corporation, Texas, 77845, USA).

\section{Results}

\section{Subject characteristics}

The general characteristics of the patients and controls are given in table 1 . The median age was 56.5 years (range: 33-85) in non-small cell lung cancer (NSCLC) patients and 56.5 years (range: $35-86$ ) in controls. One hundred and twenty one $(90.3 \%)$ patients were male, while seventy eight $(78.0 \%)$ controls were male. Twenty six $(19.4 \%)$ patients and $33(33.0 \%)$ controls were never smokers. The demographic characteristics of NSCLC patients and controls were significantly different for sex and smoking status. The characteristics of patients with NSCLC, like performance status, histology, stage, tumor size, nodal status, presence of metastasis, smoking and tobacco habits are given in table 2. Briefly, there were 103 patients with squamous cell carcinoma, and 31 with adenocarcinoma. According to TNM classification, 87 patients had stage III disease and 47 patients had stage IV disease.

\section{Correlation of patient's characteristics with survival}

At staging investigations after third cycle of chemotherapy, $16(38.1 \%)$ of the 42 patients had partial remission,

Table I: Characteristics of the subjects

\begin{tabular}{lll}
\hline Characteristics & Cases $(\mathbf{n}=\mathbf{~ I 3 4 )}$ & Controls $(\mathbf{n}=\mathbf{~ 1 0 0})$ \\
\hline $\begin{array}{l}\text { Age (years), median (range) } \ddagger \\
\text { Sex\# }\end{array} \quad 56.5(33-85)$ & $56.5(35-86)$ \\
$\quad$ Male & $121(90.3 \%)$ & $78(78.0 \%)$ \\
$\quad$ Female & $13(9.7 \%)$ & $22(22.0 \%)$ \\
Smoking status $\dagger$ & & $33(33.0 \%)$ \\
$\quad$ Never smokers & $26(19.4 \%)$ & $67(67.0 \%)$ \\
$\quad$ Smokers & $108(80.6 \%)$ & $74.5(40.3-132.0)$ \\
VEGF levels (pg/mL) & $265.7(155.7-408.0)$ & \\
Median $(25-75 \%$ quartile) & & \\
\hline
\end{tabular}

${ }^{\ddagger} p=0.642 ;{ }^{\sharp} p=0.009 ; \dagger^{\dagger}=0.026 ; * p<0.0001$ 
Table 2: The relationship between clinicopathological factors and plasma VEGF levels

\begin{tabular}{|c|c|c|c|c|}
\hline \multirow[b]{2}{*}{ Characteristics } & \multirow[b]{2}{*}{ No. (\%) } & \multicolumn{3}{|c|}{ Plasma VEGF Levels, pg/mL } \\
\hline & & Median & 25-75\% Quartile & p Value \\
\hline \multicolumn{5}{|l|}{ Age } \\
\hline$<60$ & 79 (59) & 267.4 & $169.5-454.0$ & 0.465 \\
\hline$>60$ & $55(4 I)$ & 262.7 & |46.6-385.4 & \\
\hline \multicolumn{5}{|l|}{ Sex } \\
\hline Male & $121(90.3)$ & 264.0 & $154.0-392.6$ & 0.151 \\
\hline Female & $13(9.7)$ & 338.4 & $262.0-459.4$ & \\
\hline \multicolumn{5}{|l|}{ Smoking } \\
\hline Smokers & $108(80.6)$ & 273.9 & I $73.7-442.7$ & 0.144 \\
\hline Never-smokers & $26(19.4)$ & 257.1 & $120.7-354.5$ & \\
\hline \multicolumn{5}{|l|}{ ECOG } \\
\hline I & $39(29.1)$ & 225.7 & $108.6-354.5$ & 0.062 \\
\hline $2-3$ & 95 (70.9) & 282.0 & $182.3-446.0$ & \\
\hline \multicolumn{5}{|l|}{ Histology } \\
\hline SCC & $103(76.9)$ & 276.0 & $169.5-439.5$ & 0.147 \\
\hline ADC & $31(23.1)$ & 262.0 & $132.3-338.4$ & \\
\hline \multicolumn{5}{|l|}{ Stage } \\
\hline III & $87(64.9)$ & 251.4 & $149.0-433.4$ & 0.250 \\
\hline IV & $47(35.1)$ & 276.0 & $214.0-399.4$ & \\
\hline \multicolumn{5}{|l|}{ Tumor Size } \\
\hline$<3 \mathrm{~cm}$ & $44(32.8)$ & 172.4 & $93.0-262.0$ & 0.001 \\
\hline$>3 \mathrm{~cm}$ & $90(67.2)$ & 339.9 & $218.0-484.5$ & \\
\hline \multicolumn{5}{|l|}{ T Factor } \\
\hline T2-T3 & $66(49.2)$ & 270.9 & $149.0-379.0$ & 0.653 \\
\hline $\mathrm{T} 4$ & $68(50.8)$ & 263.0 & $157.6-439.7$ & \\
\hline \multicolumn{5}{|l|}{ N Factor } \\
\hline No-NI & 65 (48.5) & 245.7 & $121.4-360.7$ & 0.082 \\
\hline N2-N3 & $69(51.5)$ & 285.7 & $192.0-439.5$ & \\
\hline \multicolumn{5}{|l|}{ M Factor } \\
\hline MO & 87 (64.9) & 251.4 & $149.0-433.4$ & 0.250 \\
\hline MI & 47 (35.1) & 276.0 & $214.0-399.4$ & \\
\hline \multicolumn{5}{|l|}{ Tobacco } \\
\hline Yes & $25(18.7)$ & 252.3 & $185.7-354.5$ & 0.524 \\
\hline No & $109(81.3)$ & 267.4 & $154.0-433.4$ & \\
\hline
\end{tabular}

VEGF, vascular endothelial growth factor; ECOG, Eastern Cooperative Oncology Group; NSCLC, non-small cell lung cancer; SCC, squamous cell carcinoma; ADC, adenocarcinoma; $T$, tumor; $N$, node; $M$, metastasis

$14(33.3 \%)$ showed progression, and $12(28.6 \%)$ had stable disease. The median survival time was 370 days $(95 \%$ $\mathrm{CI}=289.6-450.4)$. Kaplan-Meier curves for overall survival showed highly significant differences in patients with remission (R), and no change (NC) or progression $(\mathrm{P})$ at time of staging investigations after the third therapy cycle $(\mathrm{p}<0.0029$ between $\mathrm{R}$ and NC; $\mathrm{p}<0.0001$ between $R$ and $P$; Figure $1 \mathrm{~A}$ ) with median survival times of $528(\mathrm{R})$, 328 (NC), and 327 (P) days, respectively. There was no difference in overall survival time between patients with no change and progression $(\mathrm{p}=0.2857)$. For evaluation 1 , when patients with remission and stable disease $(\mathrm{R}+\mathrm{NC})$ were compared with patients having progressive disease $(P)$, a significant difference in overall survival was observed with median survival times $416(\mathrm{R}+\mathrm{NC})$ and $327(P)$ days $(p<0.0005$; Figure 1B). When patients with remission $(\mathrm{R})$ were compared with patients having pro- gressive and stable disease $(\mathrm{P}+\mathrm{NC}$; evaluation 2$)$, median survival times were $528(\mathrm{R})$ and $328(\mathrm{P}+\mathrm{NC})$ days $(\mathrm{p}<$ 0.0001; Figure 1C).

We also examined univariate survival analysis for variables including age, stage, $\mathrm{T}$ factor, nodal status, performance status, histology, smoking and tobacco habits and plasma VEGF levels (Table 3 ). Patients with a pre-treatment plasma VEGF levels $<275.2 \mathrm{pg} / \mathrm{mL}$ (median value) had a median survival of 348.0 days $(95 \% \mathrm{CI}=246.1$ 449.9), while those with $\geq 275.2$ had a median survival of 370.0 (95\% CI $=288.3-451.7$ ). The pre-treatment plasma VEGF levels did not correlate with survival $(\mathrm{p}=0.8852)$. We observed a significant correlation between tobacco habit and survival time $(\mathrm{p}=0.022$; Table 3$)$. However, no correlation between other prognostic factors with survival was observed (Table 3 ). 

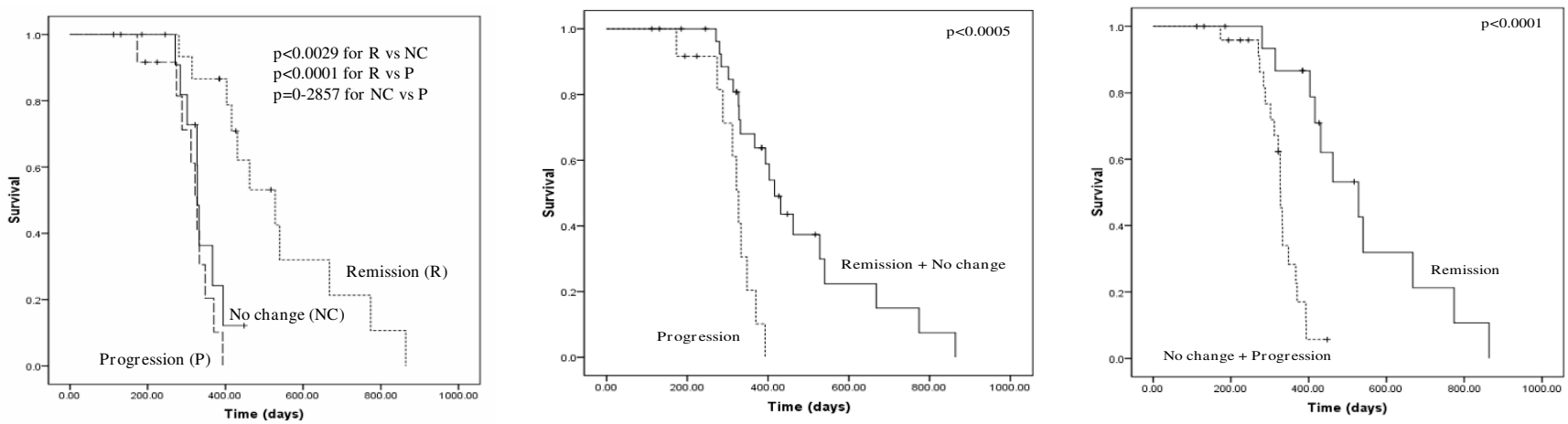

Figure I

Correlation of therapy response and overall survival. IA, Kaplan-Meier survival curves for overall survival of patients with remission $(R)$, no change $(N C)$, and progression $(P)$ at time of staging investigations after third therapy cycle. IB, for evaluation I, patients with progressive disease $(P)$ were compared with patients having remission and stable disease $(R+N C)$. IC, for evaluation 2, patients with remission $(R)$ were compared with patients having progressive and stable disease $(P+N C)$.

\section{Evaluation of plasma VEGF levels in various response groups}

We quantified plasma VEGF levels before first (BV1), second (BV2) and third (BV3) cycles of chemotherapy in 42 NSCLC patients and correlated it with response to ther- apy. Except at cycle 1 (BV1), most patients with remission had considerably lower baseline VEGF levels before the various treatment cycles (BV2 and BV3) than patients with no change and even more than patients with progressive disease (Table 4 and Figure 2).

Table 3: Univariate survival analysis of prognostic factors of NSCLC $(n=42)$

\begin{tabular}{|c|c|c|c|}
\hline Variables & $\mathbf{n}$ & Median survival ( $95 \% \mathrm{Cl}$ ) (days) & $\mathbf{P}$ \\
\hline \multicolumn{4}{|l|}{ Age (years) } \\
\hline$<60$ & 27 & $370.0(301.3-438.7)$ & 0.665 \\
\hline$\geq 60$ & 15 & $333.0(244.6-421.4)$ & \\
\hline \multicolumn{4}{|l|}{ Stage } \\
\hline III & 23 & $416.0(369.1-462.8)$ & 0.163 \\
\hline IV & 19 & $327.0(298.7-355.3)$ & \\
\hline \multicolumn{4}{|l|}{ T factor } \\
\hline T2-T3 & 17 & $431.0(315.3-546.7)$ & 0.051 \\
\hline $\mathrm{T} 4$ & 25 & $348.0(248.3-447.6)$ & \\
\hline \multicolumn{4}{|l|}{$\mathrm{N}$ factor } \\
\hline No-NI & 21 & $394.0(312.2-475.8)$ & 0.380 \\
\hline N2-N3 & 21 & $348.0(310.1-385.9)$ & \\
\hline \multicolumn{4}{|l|}{ ECOG } \\
\hline 1 & 30 & $403.0(327.9-478.0)$ & 0.130 \\
\hline $2-3$ & 12 & $333.0(311.5-354.5)$ & \\
\hline \multicolumn{4}{|l|}{ Histology } \\
\hline SCC & 31 & $367.0(288.1-445.9)$ & 0.270 \\
\hline$A D C$ & II & $394.0(324.8-463.1)$ & \\
\hline \multicolumn{4}{|l|}{ Smoking habit } \\
\hline Smokers & 36 & $370.0(294.0-446.0)$ & 0.745 \\
\hline Non-smokers & 06 & $367.0(248.7-485.3)$ & \\
\hline \multicolumn{4}{|l|}{ Tobacco habit } \\
\hline Yes & 08 & $394.0(352.3-435.6)$ & 0.022 \\
\hline No & 34 & $314.0(266.0-362.0)$ & \\
\hline \multicolumn{4}{|c|}{ Plasma VEGF (median) } \\
\hline$<275.2 \mathrm{pg} / \mathrm{mL}$ & 21 & $348.0(246.1-449.9)$ & 0.885 \\
\hline$\geq 275.2 \mathrm{pg} / \mathrm{mL}$ & 21 & $370.0(288.3-451.7)$ & \\
\hline
\end{tabular}

T, tumor; N, nodal status; ECOG, Eastern Cooperative Oncology Group; VEGF, vascular endothelial growth factor; $95 \% \mathrm{Cl}, 95 \%$ confidence interval. 
Table 4: Value distribution of VEGF in various response groups of NSCLC patients during first-line chemotherapy

\begin{tabular}{|c|c|c|c|c|c|}
\hline \multirow[b]{2}{*}{ Biomarkers (unit) } & \multirow[b]{2}{*}{$\begin{array}{l}\text { Remission median } \\
\text { (range) }\end{array}$} & \multirow[b]{2}{*}{$\begin{array}{l}\text { No Change median } \\
\text { (range) }\end{array}$} & \multirow[b]{2}{*}{$\begin{array}{l}\text { Progression median } \\
\text { (range) }\end{array}$} & \multicolumn{2}{|c|}{$\mathbf{P}$} \\
\hline & & & & $\mathbf{R}+\mathbf{N C}$ vs $\mathbf{P}$ & $R$ vs $\mathrm{NC}+\mathrm{P}$ \\
\hline VEGF BVI (pg/mL) & $364.0(136.6-868.0)$ & I $80.5(70.6-546.0)$ & $286.4(72.6-522.6)$ & 0.589 & 0.083 \\
\hline VEGF BV2 (pg/mL) & $144.0(34.6-588.4)$ & $237.8(52.1-431.0)$ & $325.2(|58.4-6| 2.1)$ & 0.001 & 0.016 \\
\hline VEGF BV3 (pg/mL) & I $19.0(26.0-571.0)$ & $269.7(51.0-526.0)$ & $402.8(|74.6-8| I .0)$ & 0.001 & 0.001 \\
\hline VEGF BVI-2 (Dec\%) & $41.6(2.2-86.8)$ & $-6.6(-90.6-64.5)$ & $-18.5(-118.2-2.7)$ & 0.0001 & 0.0001 \\
\hline VEGF BVI-3 (Dec\%) & $63.0(17.2-93.1)$ & $-3.2(-\mid 42.2-53.0)$ & $-41.0(-140.5--17.8)$ & 0.0001 & 0.0001 \\
\hline VEGF BV2-3 (Dec\%) & $12.7(-62.4-87.1)$ & $-21.2(-33.6-33.8)$ & $-15.3(-66.3-5.3)$ & 0.0268 & 0.0052 \\
\hline
\end{tabular}

BVI, BV2, and BV3, baseline VEGF levels before therapy cycle I to 3, respectively; BVI-2, BVI-3 and BV2-3, kinetics of baseline VEGF levels from cycles I to $2, I$ to 3 and 2 to 3 , respectively; Dec\%, decrease in percent (negative numbers meaning increase of the VEGF levels). $P$ values by Wilcoxon test indicate differences between patients with progressive disease $(P)$ and those having remission and stable disease $(R+N C$; evaluation $\mathrm{I})$ as well as between patients with remission $(\mathrm{R})$ and those having progressive and stable disease $(\mathrm{P}+\mathrm{NC}$; evaluation 2$)$.

When the VEGF levels at BV1, BV2 and BV3 were compared between $\mathrm{R}+\mathrm{NC}$ versus $\mathrm{P}$ (evaluation 1 ) and $\mathrm{R}$ versus $\mathrm{NC}+\mathrm{P}$ (evaluation 2), it was observed that pre-treatment VEGF levels (BV1) could not predict insufficient response to therapy and disease progression (Table 4). However, baseline VEGF levels before cycle 2 (BV2) and cycle 3 (BV3) were significantly able to predict insufficient response to therapy and disease progression. Additionally, VEGF levels showed stronger decrease from cycle 1 to 2 (BV1-2), from cycle 1 to 3 (BV1-3), and from cycle 2 to 3 (BV2-3) in patients with remission than with no change or progression (Table 4 and Figure 2). The fraction of patients with lower VEGF levels at cycle 2 (BV2) compared with at cycle 1 (BV1) in the various groups were $87.5 \%$ (R), 41.7\% (NC), and 14.3\% (P) and at cycle 3 (BV3) were $100 \%(\mathrm{R}), 50 \%(\mathrm{NC})$ and $7.1 \%(\mathrm{P})$, respectively.

\section{VEGF levels during chemotherapy for predicting} insufficient response to therapy and disease progression

To test the potential of VEGF levels as a biomarker for the prediction of insufficient therapy response, we plotted receiver-operating characteristics (ROC) curves for the values available before first (BV1), second (BV2) and third (BV3) therapy cycle (Figure 3). We did not consider plasma VEGF before cycle 1 (BV1) for predicting insufficient therapy response because of very low area under the ROC curve (AUC $=0.339$; standard error $=0.09 ; 95 \% \mathrm{CI}$ $=0.157-0.520)$. The cut-off value of plasma VEGF levels before therapy cycle 2 (BV2) was determined as $232.1 \mathrm{pg} /$ $\mathrm{mL}$ using the ROC analysis (area under the curve $=0.724$; standard error $=0.087 ; 95 \% \mathrm{CI}=0.553-0.893$ ) According to this cut-off value, we could predict insufficient therapy response with a sensitivity and specificity of $76.9 \%(95 \%$ $\mathrm{CI}=55.9-90.2)$ and $75.0 \%$ (95\% CI = 47.4-91.7), respectively (Table 5). Interestingly, we observed similar sensitivity and specificity for plasma VEGF levels available before therapy cycle 3 (BV3; area under the ROC curve = 0.817 ; standard error $=0.070 ; 95 \% \mathrm{CI}=0.679-0.956)$. For the specific prediction of insufficient response to therapy, we observed very low sensitivities of $3.8 \%$ and $11.5 \%$ at $100 \%$ specificity for the VEGF levels available before second and third cycles of chemotherapy, respectively

We also tested the relevance of VEGF levels available before first (BV1), second (BV2), and third (BV3) therapy cycle in predicting disease progression (Figure 4). Because of low value of plasma VEGF before cycle 1 (BV1) under the ROC curve, we did not consider it for predicting disease progression (AUC $=0.552$; standard error $=0.08$; $95 \% \mathrm{CI}=0.376-0.729)$. However, plasma VEGF at BV2 and BV3 most efficiently identified patients with disease progression with area under the ROC curve being 0.805 (standard error $=0.066 ; 95 \% \mathrm{CI}=0.675-0.935$ ) and 0.895 (standard error $=0.05 ; 95 \% \mathrm{CI}=0.797-0.993$ ), respectively (Figure 4). At a cut-off of $312.6 \mathrm{pg} / \mathrm{mL}$, determined from ROC curve for VEGF at BV2, we observed a sensitivity of $71.4 \%(95 \%$ CI $=42.0-90.4)$ and specificity of $71.4 \%$ (95\% CI $=51.1-86.0)$ for predicting disease progression (Table 5). Further, at $355.4 \mathrm{pg} / \mathrm{mL}$ cut-off value for VEGF at BV3, a sensitivity of $85.7 \%(95 \% \mathrm{CI}=56.2$ $97.5)$ and specificity of $89.3 \%(95 \% \mathrm{CI}=70.6-97.2)$ was achieved (Table 5). For the specific prediction of disease progression, we observed very low sensitivities of $7.1 \%$ and $21.4 \%$ at $100 \%$ specificity for the VEGF levels available before second and third cycles of chemotherapy, respectively.

\section{Circulating plasma VEGF levels as a tumor marker: calculating specificity and sensitivity using receiver- operating characteristics (ROC) curve}

The median plasma VEGF level $\left(25-75^{\text {th }}\right.$ quartile) was $265.7 \mathrm{pg} / \mathrm{mL}(155.7-408.0 \mathrm{pg} / \mathrm{mL})$ in patients with NSCLC $(\mathrm{n}=134)$ and $74.5 \mathrm{pg} / \mathrm{mL}(40.3-132.0 \mathrm{pg} / \mathrm{mL})$ in controls $(n=100)$. This difference in VEGF levels in case versus controls was highly significant $(\mathrm{p}<0.0001$; Table $1)$. 


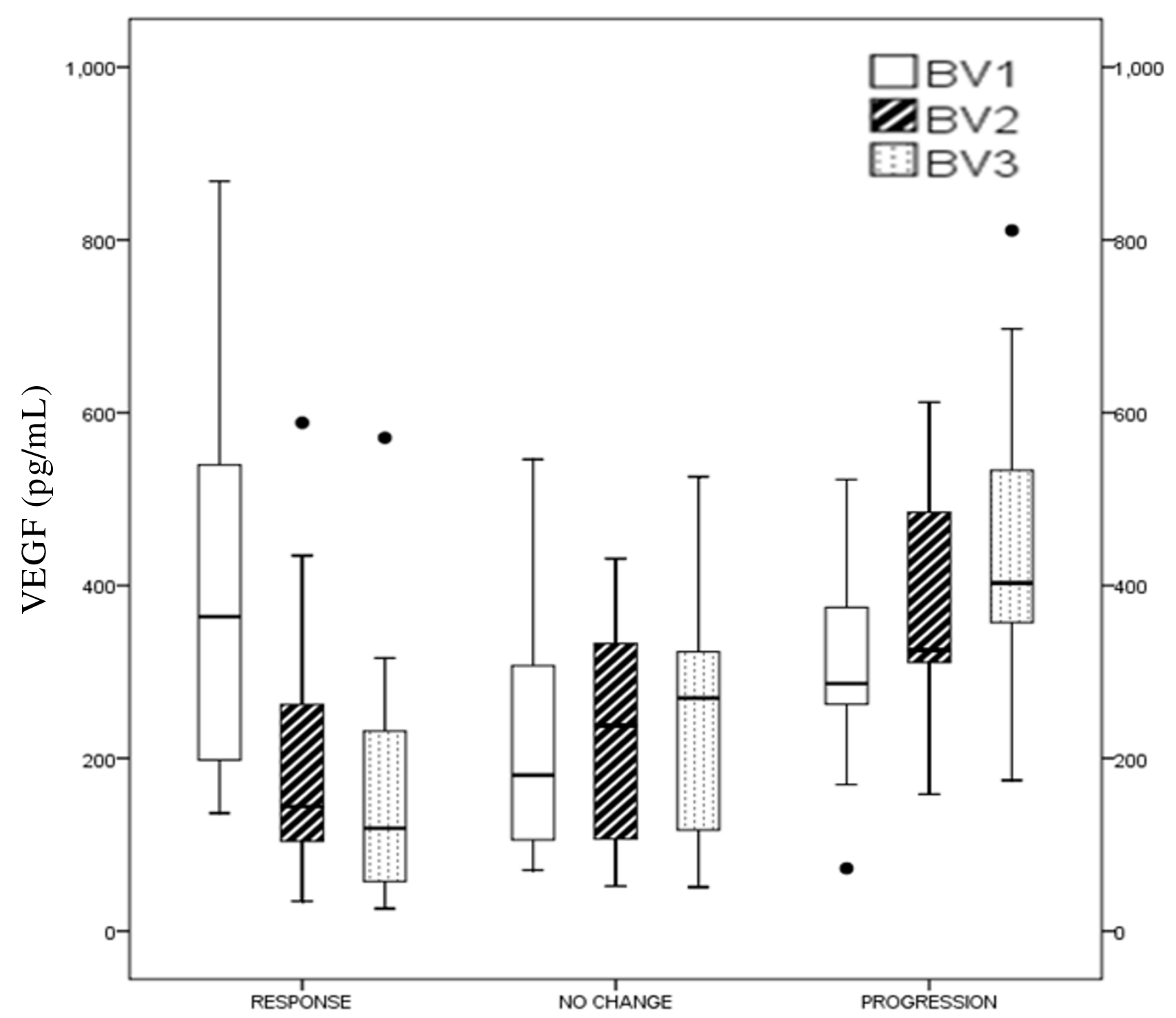

Figure 2

Distribution of plasma VEGF levels in various response groups. Median and interquartile range along with minimum and maximum values and outliers of the baseline values of the VEGF before start of therapy cycle I (pre-treatment; BVI), cycle 2 (BV2), and cycle 3 (BV3) are given.

To achieve optimum sensitivity and specificity, a VEGF concentration in patients that did not overlap with the control VEGF value would be ideal. Receiver-operating characteristics (ROC) curve was, therefore, generated for calculating the sensitivity and specificity of VEGF as a tumor marker at a selected cut-off value. The cut-off value of plasma VEGF levels was determined as $145.4 \mathrm{pg} / \mathrm{mL}$ using the ROC analysis (area under the curve $=0.8799$; standard error $=0.0213 ; 95 \% \mathrm{CI}=0.8381-0.9216$; Figure $5)$. At this cut-off, plasma levels of VEGF reached a sensi- tivity of $79.8 \%$ and a specificity of $79.0 \%$ for the detection of NSCLC. Further, at 95\% specificity, we could detect NSCLC with a sensitivity of 59.7\% (VEGF cut-off $=237.0$ $\mathrm{pg} / \mathrm{mL})$.

\section{Circulating plasma VEGF levels in correlation with various clinicopathological factors}

The relationships between various clinicopathological factors and plasma VEGF levels in the patients with lung cancer are shown in Table 2. VEGF levels were signifi- 
Table 5: Diagnostic profiles of VEGF levels available before second and third cycles of chemotherapy for the prediction of cancer progression or response to therapy

\begin{tabular}{|c|c|c|c|c|c|}
\hline & $\begin{array}{c}\text { AUC } \\
(95 \% \mathrm{Cl})\end{array}$ & $\begin{array}{c}\text { Cut-off } \\
\text { VEGF }(\mathrm{pg} / \mathrm{mL})\end{array}$ & $\begin{array}{c}\text { Sensitivity \% } \\
\text { (95\% Cl) }\end{array}$ & $\begin{array}{c}\text { Specificity \% } \\
\text { (95\% Cl) }\end{array}$ & LR \\
\hline \multicolumn{6}{|c|}{ Evaluation I $(\mathrm{R}+\mathrm{NC}$ vs $\mathrm{P})$} \\
\hline VEGF BV2 & $0.805(0.675-0.935)$ & 312.6 & $71.4(42.0-90.4)$ & $71.4(5 I .1-86.0)$ & 2.5 \\
\hline VEGF BV3 & $0.895(0.797-0.993)$ & 355.4 & $85.7(56.2-97.5)$ & $89.3(70.6-97.2)$ & 8.0 \\
\hline \multicolumn{6}{|c|}{ Evaluation 2 (R vs NC + P) } \\
\hline VEGF BV2 & $0.724(0.553-0.893)$ & 232.1 & $76.9(55.9-90.2)$ & $75.0(47.4-91.7)$ & 3.1 \\
\hline VEGF BV3 & $0.817(0.679-0.956)$ & 261.0 & $76.9(55.9-90.2)$ & $75.0(47.4-91.7)$ & 3.1 \\
\hline
\end{tabular}

BV2, and BV3, baseline VEGF levels before therapy cycle 2 to 3, respectively; AUC, area under receiver operating characteristic (ROC) curve; $95 \% \mathrm{Cl}, 95 \%$ confidence interval; LR, likelihood ratio; $R$, remission; NC, no change; $\mathrm{P}$, progression.

cantly higher in patients with tumor size $>3 \mathrm{~cm}(339.9 \mathrm{pg} /$ $\mathrm{mL}(218.0-484.5 \mathrm{pg} / \mathrm{mL})$ as compared to patients with tumor size $<3 \mathrm{~cm}(172.4 \mathrm{pg} / \mathrm{mL}(93.0-262.0) ; \mathrm{p}<0.001)$. Plasma VEGF levels were found to be higher in patients with poor performance status (PS), i.e. with a PS 2-3 compared to those with PS of 1 and in patients with higher nodal status (N2-N3) than those with N0-N1. However, these levels did not achieve statistical significance $(\mathrm{p}=$ 0.062 for PS and $\mathrm{p}=0.082$ for nodal status). There was no association between plasma VEGF levels and age, sex, smoking and tobacco habits, histology, and stage (Table 2).

\section{Discussion}

Tumor cells secrete and synthesize a number of angiogenic factors which play an important role in tumor proliferation, spread and metastasis. VEGF, one of the most potent angiogenic factors, plays a central role in the regulation of tumor angiogenesis. The current interest in targeted therapies against VEGF and its receptors has generated the need to study the course of this circulating angiogenic protein molecule during chemotherapy, to find out whether VEGF can be used in predicting prognosis and in monitoring response to therapy. Previously, some tumor biomarkers, including CYFRA 21-1, CEA and nucleosomes [4-9] have been used for predicting prognosis and estimating response to therapy. However, till date, none of them have been validated in a clinical setting. To the best of our knowledge, this is the first study which reports the kinetics of circulating VEGF levels during the course of chemotherapy in an effort to predict insufficient response to therapy and disease progression at an early stage.

In this study, we analyzed the course of circulating plasma VEGF levels at three different time points in 42 advanced stage NSCLC patients receiving platinum-based chemotherapy. VEGF levels were measured before first (BV1), second (BV2) and third (BV3) therapy cycle. These levels were then correlated with available clinical information to know whether VEGF levels could predict insufficient ther- apy response or disease progression. We found that patients with remission had significantly lower VEGF levels at BV2 and BV3 as compared to patients with no change or progression. However, at BV1, patients who went into remission had higher VEGF levels than those with no change or progression. Further, to correlate any change in VEGF levels with therapeutic response, the kinetics of VEGF levels during the course of chemotherapy was monitored. We observed a stronger decrease in VEGF levels from cycle 1 to 2 (BV1-2), from cycle 1 to 3 (BV1-3), and from cycle 2 to 3 (BV2-3) in patients with remission when compared to those with no change or progression.

Our results with VEGF are in accordance with the hypothesis that, when monitoring the efficacy of cytotoxic therapy, a substantial decrease in the levels of tumor marker often correlates with response to therapy whereas an increase or an insufficient decrease are generally associated with no response or disease progression. In our study, it was noteworthy that a significant difference in VEGF levels was observed in the response group before the start of the second therapy cycle. In a few patients who went into remission, we observed a step fall in VEGF levels to just above the reference range within this short time frame. This decrease in VEGF levels in responders may be due to the effect of cytotoxic agents on tumor cells, either by killing them or by reduction of cellular turnover, leading to a decrease in the number of cells synthesizing and secreting various angiogenic proteins, including VEGF. In this study, it was decided to evaluate VEGF levels after 2 weeks of first and second chemotherapy cycle. At such time points, it could be expected that no significant drug levels would be in circulation and that therefore, VEGF levels will reflect angiogenic activity of the residual tumor mass.

There are few studies which measured serum VEGF levels before and after chemotherapy and the data is conflicting. In a cohort of 29 patients with lung cancer, serum VEGF levels were measured before and after cisplatin-based chemotherapy [12]. A significant decrease in VEGF levels 


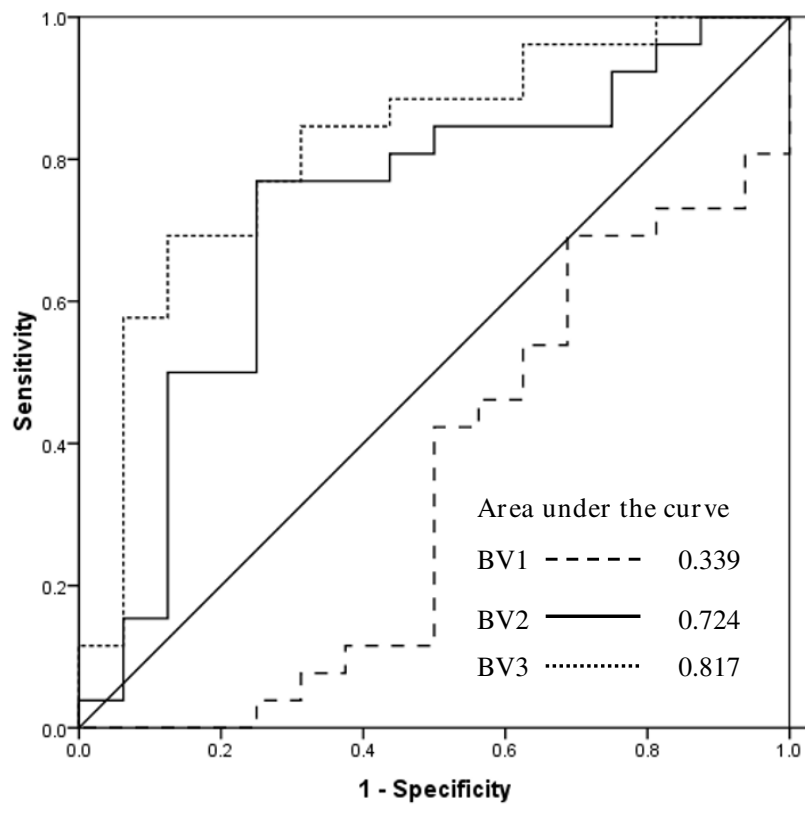

Figure 3

Receiver-operating characteristics (ROC) curves for an early estimation of response to therapy by plasma VEGF levels available before the start of therapy cycle I (BVI), cycle 2 (BV2), and cycle 3 (BV3).

was observed in responders while in non-responders, there was an increase in VEGF levels, an observation similar to ours. In another study, no difference in serum VEGF levels was observed from samples taken before first cycle after 24 hours and 48 hours of cisplatin-based chemotherapy in NSCLC patients [13]. Similarly, in a study of advanced NSCLC patients on cisplatin and gemcitabine regimen, no difference in serum VEGF levels was observed before first and after $3^{\text {rd }}$ cycles of chemotherapy [14]. In a phase II study of stage III NSCLC patients on concurrent chemoradiation given with celecoxib (COX-2 inhibitor), serum VEGF levels did not predict response [15]. Circulating VEGF levels were also used for predicting response in NSCLC patients on second-line chemotherapy. Yoshimoto et al. [16] measured serum VEGF levels before and after second-line gefitinib therapy in 52 NSCLC patients and observed no significant change after the treatment, even in responders. In a multi-centric phase II study of 58 NSCLC patients on second-line treatment, a decrease in serum VEGF levels after two cycles was significantly associated with clinical response [17]. Circulating VEGF levels have also been monitored during the course of chemotherapy in SCLC patients. Tas et al. [18] measured VEGF levels before first cycle and after $2^{\text {nd }}$ cycle of chemotherapy in 34 SCLC patients. There was no significant difference in serum VEGF levels before after cytotoxic therapy (18). In another study, a non-significant increase in serum VEGF levels was observed in both responders and non-responders after $3^{\text {rd }}$ cycle of chemotherapy in a group of 39 SCLC patients [19].

Recently, a number of studies have been done where pretreatment VEGF levels were correlated with progressionfree survival (PFS), overall survival (OS), and response to treatment in lung cancer patients being treated with antiangiogenesis drugs alone or in combination with conventional chemotherapy. In a recent study by Hanrahan et al [20] pre-treatment VEGF levels were correlated with PFS in three randomized phase II trials in advanced NSCLC. They found that, in NSCLC patients on second/third line treatment, those having low baseline plasma VEGF level had a significantly superior PFS when treated with vandetanib (VEGF receptor/EGFR receptor inhibitor) monotherapy compared with gefitinib monotherapy. Similarly, in a Japanese study, baseline plasma VEGF levels were lower in patients who experienced clinical benefit after vandetanib treatment [21]. Both studies suggest that determining pre-treatment circulating VEGF levels may have the potential to identify patients who would derive benefit from first-line targeted therapy with vandetanib. In contrast to this, in the Eastern Cooperative Oncology Group 4599 trial of carboplatin-paclitaxel with or without bevacizumab in NSCLC, high baseline plasma VEGF were associated with a greater response rate with the use of bevacizumab but not with improved survival [22]. We also observed a greater response rate in patients with higher pre-treatment plasma VEGF levels in NSCLC patients treated with platinum-based chemotherapy.

There are few reports available correlating pre-treatment VEGF levels with response to therapy and overall survival of patients treated by conventional chemotherapy. In a study on 52 advanced stage NSCLC patients treated with cisplatin plus vinorelbine, no correlation between pretreatment serum VEGF levels and response to therapy was observed [23]. This observation is similar to ours on NSCLC patients treated with platinum doublets. In contrast, Laack et al [24] reported a significant correlation between pre-treatment serum VEGF levels and response to therapy in metastatic NSCLC patients treated in a randomized phase III trial comparing gemcitabine plus vinorelbine (GV) and gemcitabine plus vinorelbine plus cisplatin (GVP). Data regarding association of VEGF levels with survival in NSCLC is conflicting, some studies showing a correlation [25-27] whereas other not being able to do so $[15,28,29]$.

In the present study, we observed a significant difference in overall survival time between patients with remission as compared to patients with no change or progression. 


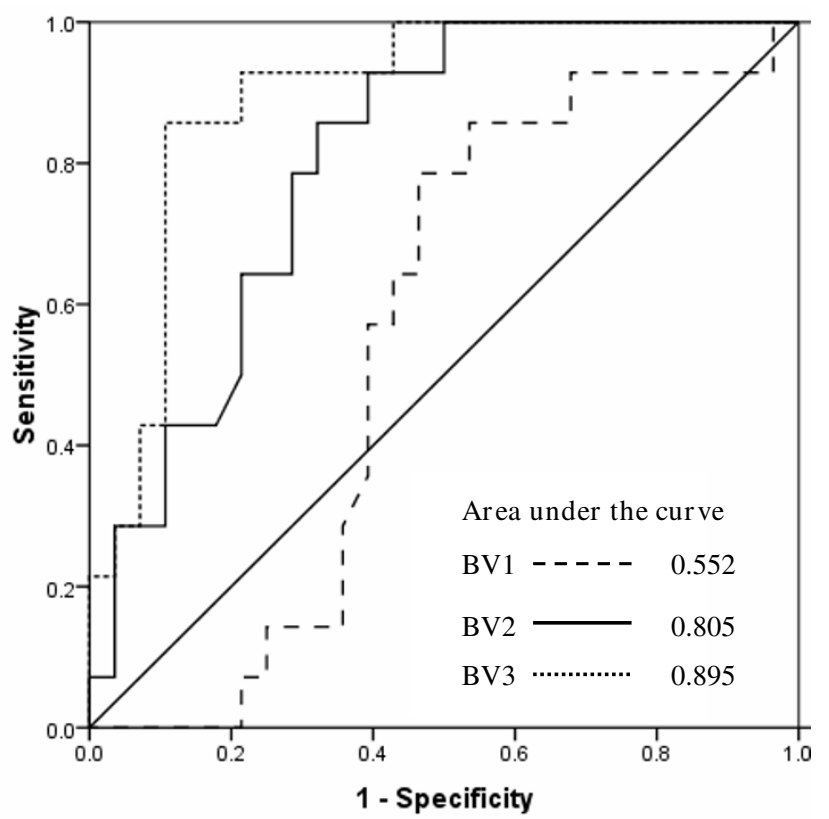

Figure 4

Receiver-operating characteristics (ROC) curves for predicting disease progression by plasma VEGF levels available before the start of therapy cycle I (BVI), cycle 2 (BV2), and cycle 3 (BV3).

During the estimation of therapy response, patients are generally grouped into responders (patients with remission) and non-responders (patients with stable disease or progression). To increase the overall survival of the patients, it is of utmost importance to find the group of patients, at an early stage of their treatment, who are either (i) going to respond to the treatment or (ii) going to progress to a more advanced stage of disease. For both these groups, it would be necessary to focus on the markers already being available before start of the second course of the treatment. This could be helpful in the better management of the cancer patients as an early prediction of response to therapy or disease progression can be used to either intensify treatment or change the treatment plan. Therefore, we conducted two different evaluations of plasma VEGF levels, available before cycle 2 of therapy (BV2), to address both clinical questions.

For evaluation $1(\mathrm{R}+\mathrm{NC}$ versus $\mathrm{P})$, we selected a VEGF (BV2) cut-off levels of $312.6 \mathrm{pg} / \mathrm{mL}$ from the ROC curve (area under the curve $=0.805$ ). At this cut-off, we were able to diagnose disease progression with a sensitivity and specificity of $71.4 \%$. While for evaluation 2 ( $\mathrm{R}$ versus $\mathrm{NC}+\mathrm{P}$ ), VEGF levels before cycle 2 (BV2) was able to predict an insufficient therapy response with a sensitivity and specificity of $76.9 \%$ and $75.0 \%$, respectively, when a cut-

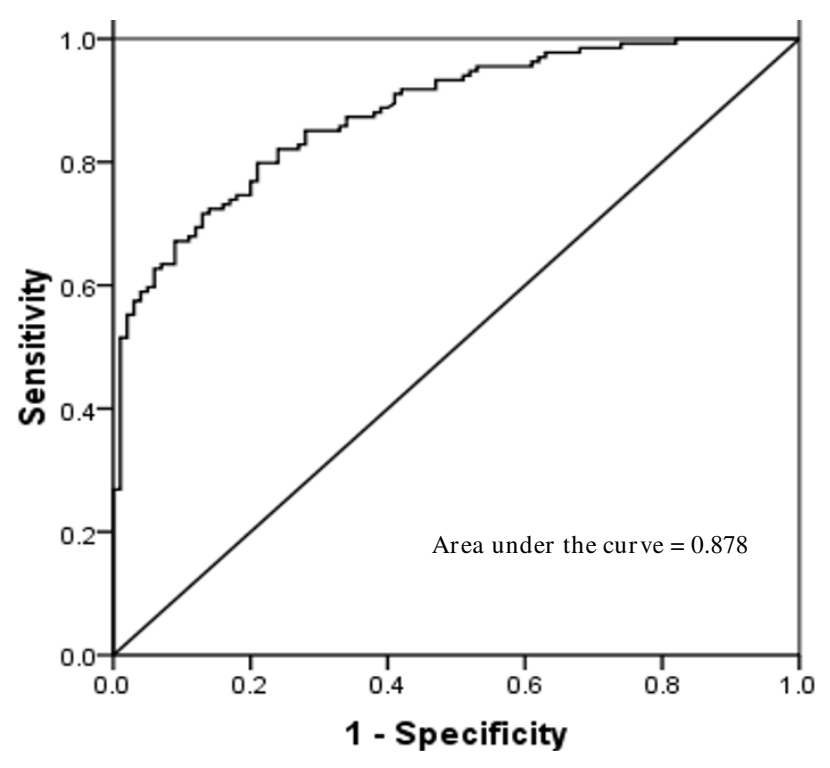

Figure 5

Receiver-operating characteristics (ROC) curve to calculate sensitivity and specificity of plasma VEGF levels as a tumor marker in advanced non-small cell lung cancer.

off of $232.1 \mathrm{pg} / \mathrm{mL}$ was applied. Interestingly, the kinetics of VEGF form cycle 1 to 2 (BV1-2) and cycle 1 to 3 (BV13) also gave significant information for predicting disease progression as well as insufficient response to therapy.

Although, our sample size was a limitation, the results show that monitoring the levels of circulating VEGF during the course of cytotoxic therapy can predict insufficient response to therapy and disease progression. Earlier studies have not evaluated measurement of levels of VEGF at defined intervals during the initial treatment phase for predicting insufficient response to therapy and disease progression in NSCLC patients. So, a large-scale prospective validation study is needed to confirm the relevance of the current findings presented here.

Further, we compared plasma VEGF levels in 134 NSCLC patients and 100 controls. Also, correlation with various clinico-pathological factors and VEGF was looked at. This study highlights a few significant findings: (a) plasma VEGF levels were significantly higher in patients with NSCLC as compared to controls; (b) significant association was observed between plasma VEGF levels and tumor size. Also, there was some evidence to suggest a correlation between plasma VEGF levels and performance status, and nodal involvement. However, these associations did not reach the level of statistical significance. 


\section{Conclusion}

In conclusion, to our knowledge, this is the first study investigating the initial changes in plasma VEGF levels for the prediction of insufficient response to therapy and disease progression in advanced NSCLC patients during firstline chemotherapy. Our results clearly show the relevance of circulating VEGF levels in differentiating responders from non-responders to therapy and in predicting disease progression. In future, such analyses could also be used for monitoring of tumor recurrence.

\section{Conflicts of interests}

The authors declare that they have no competing interests.

\section{Authors' contributions}

SK carried out the experimental work, participated in study design and manuscript preparation. RG participated in study design and manuscript drafting. VS participated in statistical analysis. ACB helped in study design and coordination. AM and BCD helped in study design, statistical analysis, and manuscript editing. All authors read and approved the final manuscript.

\section{Acknowledgements}

Sachin Kumar acknowledges Council of Scientific and Industrial Research (CSIR), Government of India (New Delhi), for providing assistance in terms of Senior Research Fellowship. The work was funded by Indian Council for Medical Research (ICMR), New Delhi, India.

\section{References}

I. Parkin DM, Bray F, Ferlay J, Pisani P: Global cancer statistics, 2002. CA Cancer J Clin 2005, 55:74-108.

2. Brambilla C, Fievet F, Jeanmart M, de Fraipont F, Lantuejoul S, Frappat V, Ferretti G, Brichon PY, Moro-Sibilot D: Early detection of lung cancer: role of biomarkers. Eur Respir / Suppl 2003, 39:36s-44s.

3. Spira A, Ettinger DS: Multidisciplinary management of lung cancer. N Eng J Med 2004, 350:379-392.

4. Holdenrieder S, Stieber P, v Pawel J, Raith H, Nagel D, Feldmann K, Seidel D: Circulating nucleosomes predict the response to chemotherapy in patients with advanced non-small cell lung cancer. Clin Cancer Res 2004, I 0:598I-5987.

5. Holdenrieder S, Stieber P, v Pawel J, Raith H, Nagel D, Feldmann K, Seidel D: Early and specific prediction of the therapeutic efficacy in lung cancer by nucleosomal DNA and cytokeratin 19 fragments. Ann NY Acad Sci 2006, I 075:244-257.

6. Vollmer RT, Govindan R, Graziano SL, Gamble G, Garst J, Kelley MJ, Christenson RH: Serum CYFRA $2 \mathrm{I}-\mathrm{I}$ in advanced stage nonsmall cell lung cancer: an early measure of response. Clin Cancer Res 2003, 9: I728-1733.

7. Stieber P, Hasholzner U, Bodenmüller H, Nagel D, Sunder-Plassmann L, Dienemann H, Meier W, Fateh-Moghadam A: CYFRA 2I-I: A new marker in lung cancer. Cancer 1993, 72:707-2I3.

8. Ebert W, Muley T: CYFRA $2 \mathrm{I}-\mathrm{I}$ in the follow-up of inoperable non-small cell lung cancer patients treated with chemotherapy. Anticancer Res 1999, 19:2669-2672.

9. Molina R, Filella X, Augé JM, Fuentes R, Bover I, Rifa J, Moreno V, Canals E, Viñolas N, Marquez A, Barreiro E, Borras J, Viladiu P: Tumor markers (CEA, CA I 25, CYFRA 2 I- I, SCC and NSE) in patients with non-small cell lung cancer as an aid in histological diagnosis and prognosis. Comparison with the main clinical and pathological prognostic factors. Tumour Biol 2003, 24:209-218.

10. Mountain CF: Revisions in the International System for Staging Lung Cancer. Chest 1997, I I I:I710-17I7.
II. Therasse P, Arbuck SG, Eisenhauer EA, Wanders J, Kaplan RS, Rubinstein L, Verweij J, Van Glabbeke M, van Oosterom AT, Christian MC, Gwyther SG: New guidelines to evaluate the response to treatment in solid tumors. J Natl Cancer Inst 2000, 92:205-216.

12. Kido Y: Vascular endothelial growth factor (VEGF) serum concentration changes during chemotherapy in patients with lung cancer. Kurume Med J 200I, 48:43-47.

13. Colakogullari M, Ulukaya E, Yilmaztepe A, Ocakoglu G, Yilmaz M, Karadag $M$, Tokullugil A: Higher serum nitrate levels are associated with poor survival in lung cancer patients. Clin Biochem 2006, 39:898-903.

14. Mihaylova Zh, Ludovini V, Gregorg V, Floriani I, Pistola L, Toffaneti F, Ferraldeschi M, Spreafico A, Ceresoli GL, Bellet M, Darwish S, Tonato $M$, Raynov J: Serum level changes of matrix metalloproteinases 2 and 9, vascular endothelial growth factor and epidermal growth factor receptor during platinum-based chemotherapy in advanced non-small cell lung cancer patients. J BUON 2007, I 2: I05-I I I.

15. Mutter R, Lu B, Carbone DP, Csiki I, Moretti L, Johnson DH, Morrow JD, Sandler AB, Shyr Y, Ye F, Choy $H$ : A phase II study of celecoxib in combination with paclitaxel, carboplatin, and radiotherapy for patients with inoperable stage IIIA/B nonsmall cell lung cancer. Clin Cancer Res 2009, I 5:2I 58-2 I65.

16. Yoshimoto A, Kasahara K, Nishio M, Hourai T, Sone T, Kimura H, Fujimura M, Nakao S: Changes in angiogenic growth factor levels after gefitinib treatment in non-small cell lung cancer. Jpn J Clin Oncol 2005, 35:233-238.

17. Gasparini G, Meo S, Comella G, Stani SC, Mariani L, Gamucci T, Avallone A, Lo Vullo S, Mansueto G, Bonginelli P, Gattuso D, Gion M: The combination of the selective cyclooxygenase-2 inhibitor celecoxib with weekly paclitaxel is a safe and active secondline therapy for non-small cell lung cancer: a phase II study with biological correlates. Cancer J 2005, I I :209-2 I6.

18. Tas F, Duranyildiz D, Oguz H, Camlica H, Yasasever V, Topuz E: Serum vascular endothelial growth factor (VEGF) and interleukin-8 (IL-8) levels in small cell lung cancer. Cancer Invest 2006, 24:492-496.

19. Ustuner Z, Saip P, Yasasever V, Vural B, Yazar A, Bal C, Ozturk B, Ozbek U, Topuz E: Prognostic and predictive value of vascular endothelial growth factor and its soluble receptors, VEGFR$I$ and VEGFR-2 levels in the sera of small cell lung cancer patients. Med Oncol 2008, 25:394-399.

20. Hanrahan EO, Ryan AJ, Mann H, Kennedy SJ, Langmuir P, Natale RB, Herbst RS, Johnson BE, Heymach JV: Baseline vascular endothelial growth factor concentration as a potential predictive marker of benefit from vandetanib in non-small cell lung cancer. Clin Cancer Res 2009, I 5:3600-3609.

21. Kiura K, Nakagawa K, Shinkai T, Eguchi K, Ohe Y, Yamamoto N, Tsuboi M, Yokota S, Seto T, Jiang H, Nishio K, Saijo N, Fukuoka M: A randomized, double-blind, phase Ila dose-finding study of vandetanib (ZD6474) in Japanese patients with non-small cell lung cancer. J Thorac Oncol 2008, 3:386-393.

22. Dowlati A, Gray R, Sandler AB, Schiller JH, Johnson DH: Cell adhesion molecules, vascular endothelial growth factor, and basic fibroblast growth factor in patients with non-small cell lung cancer treated with chemotherapy with or without bevacizumab--an Eastern Cooperative Oncology Group Study. Clin Cancer Res 2008, I4:1407-I4I2.

23. Tas F, Duranyildiz D, Oguz H, Camlica H, Yasasever V, Topuz E: Serum vascular endothelial growth factor (VEGF) and $\mathrm{Bcl}-2$ levels in advanced stage non-small cell lung cancer. Cancer Invest 2006, 24:576-580.

24. Laack E, Köhler A, Kugler C, Dierlamm T, Knuffmann C, Vohwinkel G, Niestroy A, Dahlmann N, Peters A, Berger J, Fiedler W, Hossfeld DK: Pretreatment serum levels of matrix metalloproteinase9 and vascular endothelial growth factor in non-small cell lung cancer. Ann Oncol 2002, I3:1550-I557.

25. Chakra M, Pujol JL, Lamy PJ, Bozonnat MC, Quantin X, Jacot W, Daurès JP: Circulating serum vascular endothelial growth factor is not a prognostic factor of non-small cell lung cancer. J Thorac Oncol 2008, 3: I I 19-II 26.

26. Dudek AZ, Mahaseth $\mathrm{H}$ : Circulating angiogenic cytokines in patients with advanced non-small cell lung cancer: correlation with treatment response and survival. Cancer Invest 2005, 23: 193-200. 
27. Shimanuki $Y$, Takahashi K, Cui R, Hori S, Takahashi F, Miyamoto H, Fukurchi $Y$ : Role of serum vascular endothelial growth factor in the prediction of angiogenesis and prognosis for non-small cell lung cancer. Lung 2005, 183:29-42.

28. Park JH, Choi H, Kim YB, Kim YS, Sheen SS, Choi JH, Lee HL, Lee KS, Chung WY, Lee S, Park KJ, Hwang SC, Lee KB, Park KJ: Serum angiopoietin-I as a prognostic marker in resected early stage lung cancer. Lung Cancer 2009, 66:359-364.

29. Kaminska J, Kowalska M, Kotowicz B, Fuksiewicz M, Glogowski M, Wojcik E, Chechlinska M, Steffen J: Pretreatment serum levels of cytokines and cytokine receptors in patients with non-small cell lung cancer, and correlations with clinicopathological features and prognosis. M-CSF - an independent prognostic factor. Oncology 2006, 70: I 15-125.

\section{Pre-publication history}

The pre-publication history for this paper can be accessed here:

http://www.biomedcentral.com/1471-2407/9/421/pre pub

Publish with Bio Med Central and every scientist can read your work free of charge

"BioMed Central will be the most significant development for disseminating the results of biomedical research in our lifetime. "

Sir Paul Nurse, Cancer Research UK

Your research papers will be:

- available free of charge to the entire biomedical community

- peer reviewed and published immediately upon acceptance

- cited in PubMed and archived on PubMed Central

- yours - you keep the copyright

Submit your manuscript here:

http://www.biomedcentral.com/info/publishing_adv.asp
BioMedcentral 